\title{
Transplantation of Hematopoietic Stem Cells for Primary Immunodeficiencies in Brazil: Challenges in Treating Rare Diseases in Developing Countries
}

\author{
Juliana Folloni Fernandes ${ }^{1,2}$ (D) - Samantha Nichele ${ }^{3}$. Liane E. Daudt ${ }^{4} \cdot{\text { Rita B. } \text { Tavares }^{5} \text { - Adriana Seber }}^{6}$. \\ Fábio R. Kerbauy ${ }^{2}$ - Adriana Koliski ${ }^{3}$ - Gisele Loth ${ }^{3}$ - Ana K. Vieira ${ }^{7}$ • Luiz G. Darrigo-Junior ${ }^{8}$ • Vanderson Rocha ${ }^{9,10}$. \\ Alessandra A. Gomes ${ }^{9}$. Vergílio Colturato ${ }^{11}$ • Luiz F. Mantovani ${ }^{1,2}$. Andreza F. Ribeiro ${ }^{2}$. Lisandro L. Ribeiro ${ }^{3,12}$. \\ Cilmara Kuwahara ${ }^{13}$ - Ana L. M. Rodrigues ${ }^{13}$ • Victor G. Zecchin ${ }^{6}$ • Beatriz T. Costa-Carvalho ${ }^{14}$. \\ Magda Carneiro-Sampaio ${ }^{1,15} \cdot$ Antonio Condino-Neto $^{16} \cdot$ Anders Fasth $^{17} \cdot$ Andrew Gennery $^{18} \cdot$ Ricardo Pasquini $^{3,12}$. \\ Nelson Hamerschlak ${ }^{2}$. Carmem Bonfim ${ }^{3,12,13}$
}

Received: 31 January 2018 / Accepted: 18 October 2018 / Published online: 24 November 2018

(C) Springer Science+Business Media, LLC, part of Springer Nature 2018

\begin{abstract}
The results of hematopoietic stem cell transplant (HSCT) for primary immunodeficiency diseases (PID) have been improving over time. Unfortunately, developing countries do not experience the same results. This first report of Brazilian experience of HSCT for PID describes the development and results in the field. We included data from transplants in 221 patients, performed at 11 centers which participated in the Brazilian collaborative group, from July 1990 to December 2015. The majority of transplants were concentrated in one center $(n=123)$. The median age at HSCT was 22 months, and the most common diseases were severe combined immunodeficiency (SCID) $(n=67)$ and Wiskott-Aldrich syndrome (WAS) $(n=67)$. Only 15 patients received unconditioned transplants. Cumulative incidence of GVHD grades II to IV was 23\%, and GVHD grades III to IV was $10 \%$. The 5-year overall survival was $71.6 \%$. WAS patients had better survival compared to other diseases. Most deaths $(n=53)$ occurred in the first year after transplantation mainly due to infection (55\%) and GVHD (13\%). Although transplant for PID patients in Brazil has evolved since its beginning, we still face some challenges like delayed diagnosis and referral, severe infections before transplant, a limited number of transplant centers with expertise, and resources for more advanced techniques. Measures like newborn screening for SCID may hasten the diagnosis and ameliorate patients' conditions at the moment of transplant.
\end{abstract}

Juliana Folloni Fernandes

j.fernandes@hc.fm.usp.br

1 Instituto da Criança - Hospital das Clínicas da Universidade de São Paulo, São Paulo, Brazil

2 Hospital Israelita Albert Einstein, São Paulo, SP, Brazil

3 Hospital de Clínicas da Universidade Federal do Paraná, Curitiba, Brazil

4 Hospital de Clínicas de Porto Alegre - Universidade Federal do Rio Grande do Sul, Porto Alegre, Brazil

5 Instituto Nacional do Cancer, Rio de Janeiro, Brazil

6 Instituto de Oncologia Pediátrica, Universidade Federal de São Paulo, São Paulo, Brazil

7 Hospital de Clínicas da Universidade Federal de Minas Gerais, Belo Horizonte, Brazil

8 Hospital das Clínicas da Universidade de São Paulo, Ribeirão Preto, Brazil
9 Hospital Sírio Libanês, São Paulo, Brazil

10 Churchill Hospital, University of Oxford, NHS-BT, Oxford, UK

11 Hospital Amaral Carvalho, Jaú, São Paulo, Brazil

12 Hospital Nossa Senhora das Graças, Curitiba, Brazil

13 Hospital Infantil Pequeno Príncipe, Curitiba, Brazil

14 Grupo Brasileiro de Imunodeficiências, BRAGID, São Paulo, Brazil

15 Consórcio Brasileiro de Centros de Referência em Imunodeficiências Primárias, CoBID, São Paulo, Brazil

16 Department of Immunology, Institute of Biomedical Sciences, and Institute of Tropical Medicine, University of São Paulo, São Paulo, SP, Brazil

17 Department of Pediatrics, University of Gothenburg, Gothenburg, Sweden

18 Great North Children's Hospital, Newcastle-Upon-Tyne, United Kingdom 
Keywords Primary immunodeficiencies · stem cell transplantation · severe combined immunodeficiency · Wiskott-Aldrich syndrome $\cdot$ Latin America

\section{Introduction}

Primary immunodeficiency diseases (PID) are a heterogeneous group of rare monogenic disorders that affect innate or adaptive immunity, resulting in susceptibility to lifethreatening infections, autoimmunity, autoinflammation, and increased risk of malignancy. More than 350 different PIDs with mutations in genes coding for elements of the immune system are described. Many of these diseases have been successfully treated by hematopoietic stem cell transplantation (HSCT) [1-5]. In these rare disorders, single-center reports of small cohorts are of limited value. For that reason, both Europe (IEWP/EBMT (Inborn Errors Working Party/European Group for Blood and Marrow Transplantation) in collaboration with ESID (European Society for Immunodeficiency)) and USA (PIDTC (Primary Immune Deficiency Treatment Consortium) and the CIBMTR (Center for International Blood and Marrow Transplant Research)) formed collaborative groups to study outcomes of HSCT in PID, elaborate protocols to standardize treatment in participating institutions, and develop prospective interventional trials [6-10]. The most recent EBMT/ESID publication reported the outcomes of almost 1500 patients with SCID and nonSCID PID, showing a significant improvement on overall survival since 2000 , especially for patients receiving transplants with alternative donors [5].

The Latin American Group for Immunodeficiencies (LAGID) was created in 1993 to study the prevalence of PID in the region and to promote awareness and earlier diagnosis of these diseases. Since 2009, this group evolved into an active society, LASID (Latin American Society for Immunodeficiencies) that works to establish a registry covering all Latin American countries, develop effective educational programs, improve diagnosis and optimal care for these patients, and foster collaboration within the region and internationally. The development of a robust registry resulted in many collaborative studies published in recent years [11-16].

The first child with PID transplanted in Latin America had X-linked SCID and received a Campath-1 M T celldepleted haploidentical transplant in Costa Rica in November 1985 [17]. Despite important progress in HSCT in this region, access to HSCT for PID varies dramatically across Latin American countries and even within the same country. A survey performed in 2015 showed that only nine countries had transplanted patients with PID (Brazil, Argentina, Mexico, Uruguay, Peru, Colombia, Chile, Venezuela, and Costa Rica) [18].
Brazil is the largest Latin American country with over 200 million inhabitants and approximately 3 million live births a year. Since 1985, groups like the Brazilian Group for Immunodeficiencies (BRAGID) and the Brazilian Consortium for Immunodeficiencies (CoBID) collect data on PID patients and disseminate knowledge about these diseases among physicians and the general population $[19,20]]$. The first Brazilian HSCT was performed in 1979 at the Federal University of Parana, but only in 1990 was the first patient with PID (Chediak-Higashi Syndrome) transplanted at the National Cancer Institute in Rio de Janeiro. From personal communications at the beginning to the participation of international committees and studies (EBMT, PIDTC, CIBMTR), as well as networking with experienced transplant physicians, this collaboration has enabled significant progress in the field, both in numbers and quality of care [10, 21-24].

The Pediatric study group of the Brazilian Society of Bone Marrow Transplantation (SBTMO) was stablished in 2002 aiming to address important questions regarding the outcome of children and adolescents undergoing HSCT and to establish collaboration among centers. Since its creation, the collaboration between pediatric transplant centers in Brazil has progressed and several retrospective studies have been performed in children with malignant and non-malignant diseases, making it possible to draw a picture of what has been achieved and raise questions to be answered in coming prospective studies. This is the first report of results of HSCT for PID in Brazil.

\section{Methods}

From July 1990 to December 2015, 11 centers participating in the Pediatric SBTMO study group reported transplants for children with PID. Retrospective data on HSCT, including donor type, stem cell source, conditioning regimen, and graft-versus-host disease (GVHD) prophylaxis were collected from patient charts at each center.

\section{Endpoints}

For patients receiving preparatory regimen and having survived more than 28 days, neutrophil recovery was defined as absolute neutrophil count above $0.5 \times 10[9] / \mathrm{L}$ for three consecutive days. Chimerism analysis when available was done in whole blood by VNTR or STR techniques. Graft failure was defined by the absence of neutrophil recovery or the presence of at least $95 \%$ recipient chimerism. Acute graft-versushost disease (aGVHD) was diagnosed and graded according 
to the Glucksberg criteria [25]. Patients that survived for more than 100 days after transplantation were evaluated for the presence of chronic graft-versus-host disease (cGVHD), which was diagnosed according to standard criteria [26]. Overall survival time was defined as the time between transplantation and death from any cause. This study was approved by the Institutional Review Boards of each center and performed in accordance with the 1964 Declaration of Helsinki.

\section{Statistical Analysis}

Descriptive statistics were calculated as median and range for quantitative variables and frequencies and percentiles for categorical variables. Comparisons between groups were performed using the likelihood ratio test. Probabilities of survival after transplantation were calculated with the use of the KaplanMeier estimator; data were censored at day of last follow-up. The cumulative incidences of aGVHD and cGVHD were estimated considering death as a competing event with a $95 \%$ confidence interval $(95 \% \mathrm{CI})$. Multivariate analyses were performed using a Cox proportional hazard model for OS, stepwise selection with backward criteria. Significant differences were defined as a $p$ value $\leq 0.05$. Analyses were performed using IBM SPSS Statistics for Windows (version 20.0. Armonk, NY) and the " $\mathrm{R}$ " statistical software version 2.2.7 (R Core Team, http://www.R-project.org).

\section{Results}

\section{Patients' Characteristics}

From July 1990 to December 2015, 221 patients underwent HSCT for PID in 11 Brazilian centers. Four reference centers contributed the majority of patients (Federal University of Paraná, $n=123$; Albert Einstein Hospital, $n=34$; University of São Paulo, $n=17$; Federal University of Rio Grande do Sul, $n=12$ ), while the other seven centers reported 35 patients. Ten received transplants before 1999, 22 from 2000 to 2004, 58 from 2005 to 2009, and 131 from 2010 to 2015. Disorders were grouped into three categories: SCID $(n=67)$, WiskottAldrich syndrome $(n=67)$, and other PID $(n=87)$. Comparing the four periods of time, there were more patients with other PID in the most recent group compared to previous periods $(p=0.001)$. Median age at HSCT was 22 months (range 1-444), 12 months for SCID (range 1-126), 27 months for WAS (range 5-179), and 29 months (range 4-444) for the other diseases (Table 1).

In the SCID group, the genetic diagnosis was available only for 18 of 67 patients. Data on BCG vaccination was available for 60 of 67 SCID patients: 7 of 60 were not vaccinated before transplantation. Twenty-eight of the 53 vaccinated infants developed disseminated BCG infections.

\section{Transplantation}

Characteristics of donors and transplants are shown in Table 2. Donors were matched sibling donor (MSD), $n=38$; other matched related (MRD), $n=8$; matched unrelated donor (MUD), $n=65$; mismatched unrelated (MMUD), $n=83$; and mismatched related (MMRD, haploidentical), $n=27$. Stem cell source was as follows: bone marrow, $n=126$; peripheral blood, $n=8$; and cord blood, $n=87$. Twenty-two T cell-depleted haploidentical donor transplants were performed, 3 with E-rosette depletion, 6 with in vitro $\mathrm{CD} 34+$ selection, and the remaining 13 with in vivo $\mathrm{T}$ cell depletion using post-transplantation cyclophosphamide. Fifteen patients received unconditioned infusions, 32 received melphalan-based conditioning, 149 received busulfan-based conditioning, and 27 received other types of conditioning. GVHD prophylaxis was based on cyclosporine in the majority of patients $(n=$ 185), mainly associated with methotrexate, mycophenolate, or steroids. Most patients received serotherapy $(70 \%)$ with either rabbit antithymocyte globulin (r-ATG, $n=138)$ or alemtuzumab $(n=17)$. Comparing the four time periods, in the more recent cohort, there were more patients transplanted with alternative donors, cord blood as cell source, and serotherapy in the conditioning regimen.

\section{Engraftment and GVHD}

Fifteen patients died before 28 days post-HSCT and were not evaluable for engraftment. Causes of death for these patients were infection $(n=9)$, sinusoidal obstruction syndrome $(n=3)$, and other transplant-related toxicity $(n=3)$. Of the 206 evaluable patients, 178 engrafted (86\%), considering neutrophil recovery and/or chimerism over $5 \%$ donor cells on whole blood chimerism. Chimerism analysis was available for 173 out of the 206 patients, 24 had donor chimerism $<5 \%, 54$ had mixed chimerism (5-95\%donor), and 95 had complete donor chimerism (>95\%). All 15 SCID patients that were transplanted without chemotherapy and engrafted had mixed chimerism. Primary graft failure occurred in 28 patients, and 13 underwent a second transplant. Twenty-one patients had secondary graft failure after initial engraftment. Of these, 14 received a second transplant. In a univariate analysis, patients receiving UCB had a higher incidence of graft failure compared to those receiving $\mathrm{BM}$ as cell source (data not shown). A multivariate analysis for graft failure was not possible as full information for other important risk factors like infections at the time of transplant was not completely available for all patients.

Cumulative incidence of acute GVHD (aGVHD) grades II to IV was $23 \%$ (95\% CI $17 \%$ to $29 \%$ ), and the cumulative incidence of aGVHD grades III to IV was 
Table 1 Patients characteristics

\begin{tabular}{|c|c|c|c|c|c|c|c|}
\hline & & 1992-1999 & 2000-2004 & 2005-2009 & 2010-2015 & Total & $p$ value* \\
\hline Total $(n)$ & & 10 & 22 & 58 & 131 & 221 & \\
\hline Median age (months) & & 13.5 & 15 & 19.5 & 25 & 22 & 0.37 \\
\hline$\leq 6 \mathrm{~m}$ & & 1 & 3 & 3 & 5 & 12 & \\
\hline$>6 \mathrm{~m}$ & & 9 & 19 & 55 & 126 & 209 & \\
\hline Sex (no. $(\%))$ & & & & & & & 0.33 \\
\hline Male & & 9 & 20 & 47 & 101 & 177 & \\
\hline Female & & 1 & 2 & 11 & 30 & 44 & \\
\hline Diagnosis (no. (\%)) & & & & & & & 0.001 \\
\hline SCID & & 6 & 9 & 16 & 36 & 67 & \\
\hline T-B-NK- & & 1 & 1 & 1 & 4 & 7 & \\
\hline $\mathrm{T}-\mathrm{B}-\mathrm{NK}+$ & & 1 & 4 & 5 & 12 & 22 & \\
\hline $\mathrm{T}-\mathrm{B}+\mathrm{NK}-$ & & 3 & 2 & 2 & 11 & 18 & \\
\hline $\mathrm{T}-\mathrm{B}+\mathrm{NK}+$ & & - & 1 & 2 & 1 & 4 & \\
\hline Undefined & & 1 & 1 & 6 & 8 & 16 & \\
\hline WAS & & 2 & 11 & 24 & 30 & 67 & \\
\hline \multicolumn{8}{|l|}{ Other PID } \\
\hline \multirow[t]{3}{*}{ Phagocytic disorders } & & 1 & 1 & 3 & 27 & 32 & \\
\hline & CGD & - & 1 & 1 & 22 & 24 & \\
\hline & Congenital neutropenia & 1 & - & 2 & 5 & 8 & \\
\hline \multirow[t]{6}{*}{ Immune dysregulation } & & 1 & 1 & 4 & 25 & 31 & \\
\hline & FHLH & - & 1 & 1 & 10 & 12 & \\
\hline & CHS & 1 & - & 3 & 9 & 13 & \\
\hline & Griscelli syndrome & - & - & - & 2 & 2 & \\
\hline & IPEX syndrome & - & - & - & 3 & 3 & \\
\hline & XLP1 & - & - & - & 1 & 1 & \\
\hline Combined immunodeficiency & & - & - & 1 & 6 & 7 & \\
\hline Other & & - & - & 10 & 12 & 22 & \\
\hline
\end{tabular}

SCID severe combined immunodeficiency; WAS Wiskott-Aldrich syndrome; PID primary immune deficiency; CGD Chronic Granulomatous Disease; FHLH familial hemophagocytic lymphohistiocytosis; CHS Chediak-Higashi Syndrome; IPEX immunedysregulation, polyendocrinopathy, enteropathy, $\mathrm{X}$-linked; XLP X-linked lymphoproliferative disease

*Comparison of frequencies for the characteristics between the four time periods

$10 \%$ (95\% CI $6 \%$ to $14 \%$ ). There was no difference on the incidence of aGHVD regarding type of donor, cell source, or diagnosis. The cumulative incidence of chronic GVHD was $12 \%$ (95\% CI 8 to $17 \%$ ), and $6 \%$ (95\% CI 3 to $9 \%$ ) were extensive.

\section{Survival}

With a median follow-up of 57 months, the 5-year overall survival was $71.6 \%$ (95\% CI $65 \%$ to $78 \%$ ) (Fig. 1). Most deaths (53 patients) occurred in the first year after transplantation, and only three patients died after 5 years. The major cause of death was infection ( 35 of 64 deaths, 55\%), followed by GVHD ( 8 of 64 deaths, 13\%). For the 27 patients that had graft rejection and received a second transplant, overall survival at 5 years was $61 \pm 10 \%$ (95\% CI $41 \%$ to $80 \%)$. The overall survival at 5 years for SCID was $68 \%$ (95\% CI $56 \%$ to $79 \%$ ). Particularly in the SCID group, disseminated BCGosis was not associated with a poorer survival (data not shown), and one explanation could be the low number of patients in this group. For the 67 patients transplanted for WAS, 5-year survival rate was $80 \%$ (95\% CI $70 \%$ to $90 \%$ ) (Fig. 2). There was no difference in survival over time comparing the four time periods since 1990 (Fig. 3).

In a multivariate analysis model including donor type, stem cell source, period of transplant, age, gender, and diagnosis, the only factors associated with a better survival were BM as stem cell source and WAS diagnosis (Table 3 ). There was a trend for patients with lower age, and receiving transplants for MSD compared to MMRD to have a better OS, but these have not reached statistical significance probably because of the low numbers of patients of this cohort. 
Table 2 Transplant characteristics

\begin{tabular}{|c|c|c|c|c|c|c|}
\hline & $\begin{array}{l}1992- \\
1999\end{array}$ & $\begin{array}{l}2000- \\
2004\end{array}$ & $\begin{array}{l}2005- \\
2009\end{array}$ & $\begin{array}{l}2010- \\
2015\end{array}$ & Total & $p$ value* \\
\hline Total $(n)$ & 10 & 22 & 58 & 131 & 221 & \\
\hline Donor & & & & & & $<0.001$ \\
\hline MSD & 4 & 8 & 5 & 21 & 38 & \\
\hline MUD & - & 5 & 14 & 46 & 65 & \\
\hline MRD & - & 1 & 4 & 3 & 8 & \\
\hline MMUD & 3 & 6 & 34 & 40 & 83 & \\
\hline MMRD & 3 & 2 & 1 & 21 & 27 & \\
\hline Source of stem cells & & & & & & $<0.001$ \\
\hline $\mathrm{BM}$ & 8 & 13 & 20 & 85 & 126 & \\
\hline $\mathrm{CB}$ & 2 & 9 & 34 & 36 & 85 & \\
\hline PBSC & - & - & - & 10 & 10 & \\
\hline Conditioning regimen & & & & & & $<0.001$ \\
\hline No conditioning & 3 & 4 & 5 & 3 & 15 & \\
\hline Busulfan only & - & 2 & 5 & 1 & 8 & \\
\hline Busulfan $+\mathrm{Cy}$ & 5 & 12 & 33 & 30 & 80 & \\
\hline Busulfan + Flu & - & 3 & 3 & 50 & 56 & \\
\hline Melphalan based & - & 1 & 12 & 19 & 32 & \\
\hline $\mathrm{Flu}+\mathrm{Cy}+\mathrm{TBI} 2 \mathrm{~Gy}$ & - & - & - & 17 & 17 & \\
\hline Other & 2 & - & - & 11 & 13 & \\
\hline Seroterapy & & & & & & $<0.001$ \\
\hline None & 9 & 13 & 14 & 30 & 66 & \\
\hline ATG & 1 & 9 & 43 & 85 & 138 & \\
\hline Alemtuzumab & - & - & 1 & 16 & 17 & \\
\hline GVHD prophylaxis & & & & & & $<0.001$ \\
\hline None & - & 3 & 1 & 1 & 5 & \\
\hline $\mathrm{CsA} / \mathrm{FK}$ & 1 & 3 & 6 & 8 & 18 & \\
\hline $\mathrm{CsA} / \mathrm{FK}+\mathrm{MTX}$ & 3 & 5 & 30 & 53 & 91 & \\
\hline $\mathrm{CsA} / \mathrm{FK}+\mathrm{MMF}$ & - & 1 & 4 & 25 & 30 & \\
\hline $\mathrm{CsA} / \mathrm{FK}+$ steroids & 2 & 10 & 16 & 18 & 46 & \\
\hline CD34 selection & - & - & - & 6 & 6 & \\
\hline $\mathrm{Pt} \mathrm{Cy}+\mathrm{FK} / \mathrm{CsA}+\mathrm{MMF}$ & - & - & - & 19 & 19 & \\
\hline Other & - & - & 1 & 1 & 6 & \\
\hline Engraftment & & & & & & 0.65 \\
\hline Yes & 9 & 16 & 48 & 108 & 181 & \\
\hline No & 1 & 6 & 10 & 23 & 40 & \\
\hline Acute GVHD & & & & & & 0.25 \\
\hline None-I & 4 & 14 & 41 & 103 & 162 & \\
\hline II & 3 & 4 & 8 & 17 & 32 & \\
\hline III-IV & 3 & 3 & 8 & 11 & 25 & \\
\hline Missing & - & 1 & 1 & - & 2 & \\
\hline Second transplant & 0 & 2 & 9 & 16 & 27 & 0.34 \\
\hline Alive & & & & & & 0.49 \\
\hline Yes & 7 & 15 & 37 & 98 & 157 & \\
\hline No & 3 & 7 & 21 & 33 & 64 & \\
\hline Cause of death $(n)$ & 3 & 7 & 21 & 33 & 64 & 0.03 \\
\hline Infection & 2 & 2 & 7 & 24 & 35 & \\
\hline VOD/IPS & - & 1 & 4 & 1 & 6 & \\
\hline GVHD & - & - & 4 & 4 & 8 & \\
\hline
\end{tabular}


Table 2 (continued)

\begin{tabular}{llllll}
\hline & $\begin{array}{l}1992- \\
1999\end{array}$ & $2000-$ & $2005-$ & $2010-$ & Total \\
& 2004 & 2009 & - & 4 \\
Rejection & 1 & 1 & 2 & 2 & 4 \\
Other & - & 1 & 1 & 2 & 7 \\
Missing & - & 2 & 3 & 2 & 7 \\
\hline
\end{tabular}

$M S D$ matched sibling donor, $M U D$ matched unrelated donor, $M R D$ matched related donor, $M M U D$ mismatched unrelated donor, $M M R D$ mismatched related donor, $B M$ bone marrow, $C B$ cord blood, $P B S C$ peripheral blood stem cells, $F l u$ fludarabine, $C y$ cyclophosphamide, $T B I$ total body irradiation, $A T G$ anti-thymocyte globulin, $G V H D$ graft-versus-host disease, $C s A$ cyclosporine A, $F K$ tacrolimus, $M T X$ methotrexate, $M M F$ mycophenolate mophetil, $P T C y$ post-transplant cyclophosphamide, VOD veno-occlusive disease of the liver, IPS interstitial pneumonia syndrome

*Comparison of frequencies for the characteristics between the four time periods

\section{Discussion}

This study reports the 25-year experience of HSCT for PID in Brazil. Despite increasing numbers of patients and spectrum of diseases transplanted in our country, this is still less than expected considering the numbers of patients with PID in need of a transplant. A number of reasons may explain this, including the diagnostic challenges, and delayed referral to reference centers and transplant units. A progressive increase in numbers of transplants was found, especially since 2010 , when numbers doubled compared to previous time periods. This could be explained by the increasing awareness of PID by pediatricians and immunologists and a more pro-active approach from transplant centers interested in treating these patients. During recent years, close contact between immunologists and transplant centers facilitated timely referral. Yet, there are still a lack of beds for these patients as few specialized pediatric HSCT units are available in the country and only about five care for PID at the present time. During the time of our study, some centers stopped performing transplants in PID mostly for the high costs of this transplants and some for adverse outcomes in the beginning. Despite the increase in numbers, we did not find any difference in overall survival through the different time periods (Fig. 3). This may be because as the number of patients increased, so did the complexity of transplants, with more severe diseases and a successively more frequent use of alternative donors.

In patients with SCID, the identification of specific genotypes is progressively gaining importance in HSCT outcomes $[27,28]$. Preparatory regimens may change according to specific types of SCID; ADA deficiency or DCLRE1C mutation (ARTEMIS deficiency, associated with DNA repair disorders) are described as having poorer outcomes as compared to other

Fig. 1 Five-year overall survival for the entire cohort

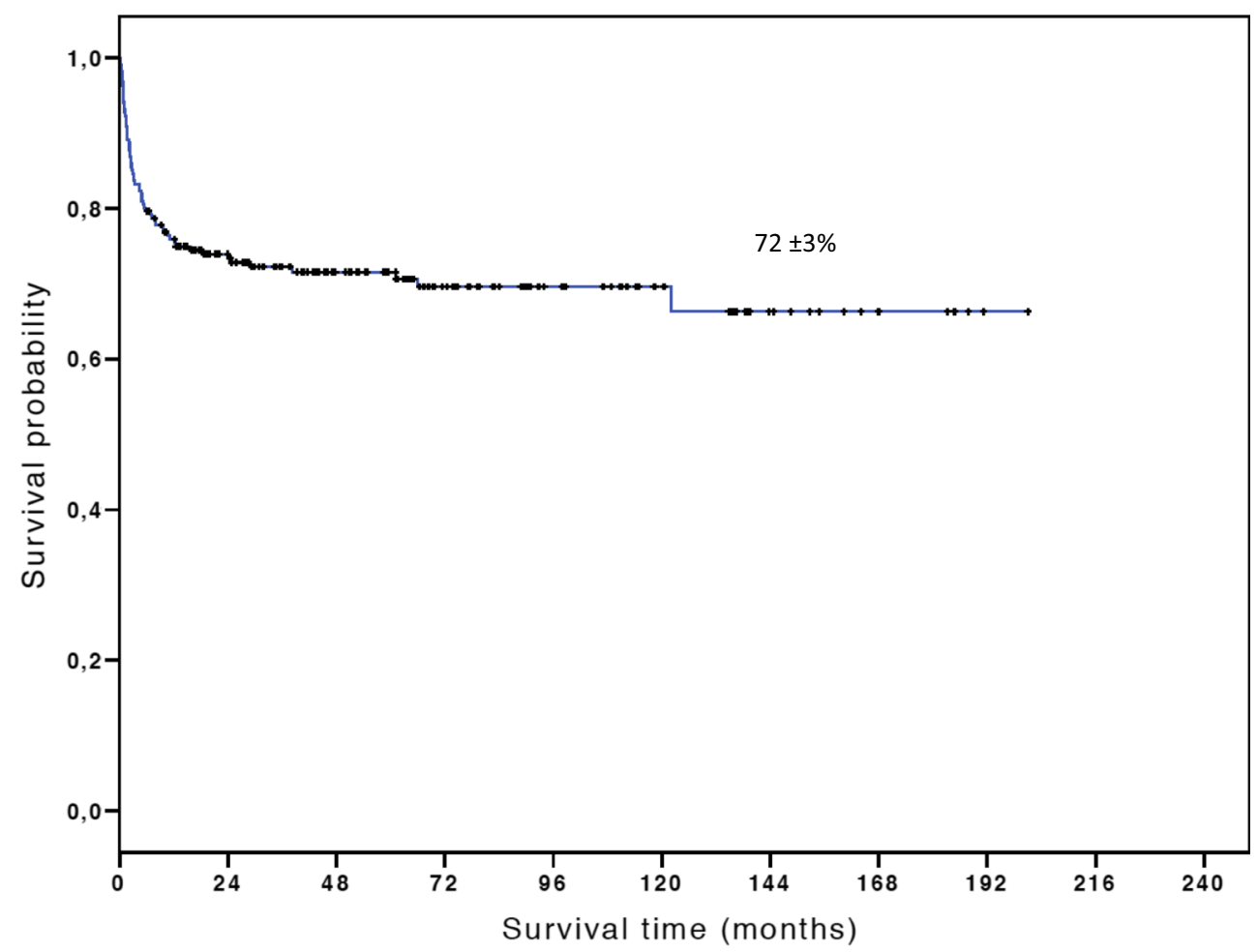


Fig. 2 Five-year overall survival by disease type (SCID vs WAS vs other)

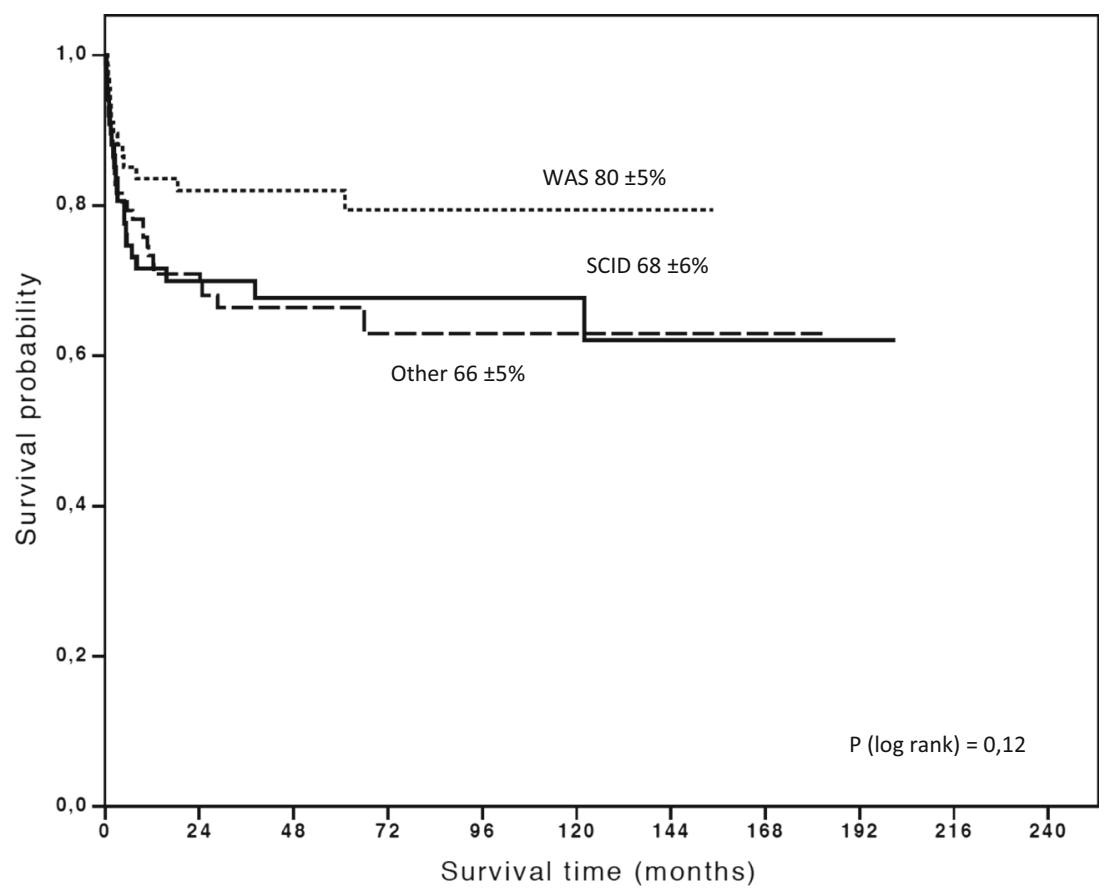

types of SCID, needing a less intense conditioning regimen, while RAG mutations generally need more intense preparative regimens [29, 30]. In our cohort, the majority of SCID patients did not have a genetic diagnosis. This is improving as groups like BRAGID and CoBID are improving access to genetic diagnoses for different regions of the country, previously restricted only to a few reference centers.
In Brazil, BCG vaccination occurs at birth, before infants are discharged from hospital. BCG vaccine may cause very severe disseminated infections in immunocompromised patients, especially SCID and other PID, like CGD [31]. Among 70 Brazilian SCID patients reported, 60 had received BCG vaccination at birth, $65 \%$ had complications of the vaccine, $50 \%$ with disseminated $\mathrm{BCG}$ infection [32]. It is recognized that $\mathrm{BCG}$

Fig. 3 Five-year overall survival by disease period (until 19992004-2009-2015)

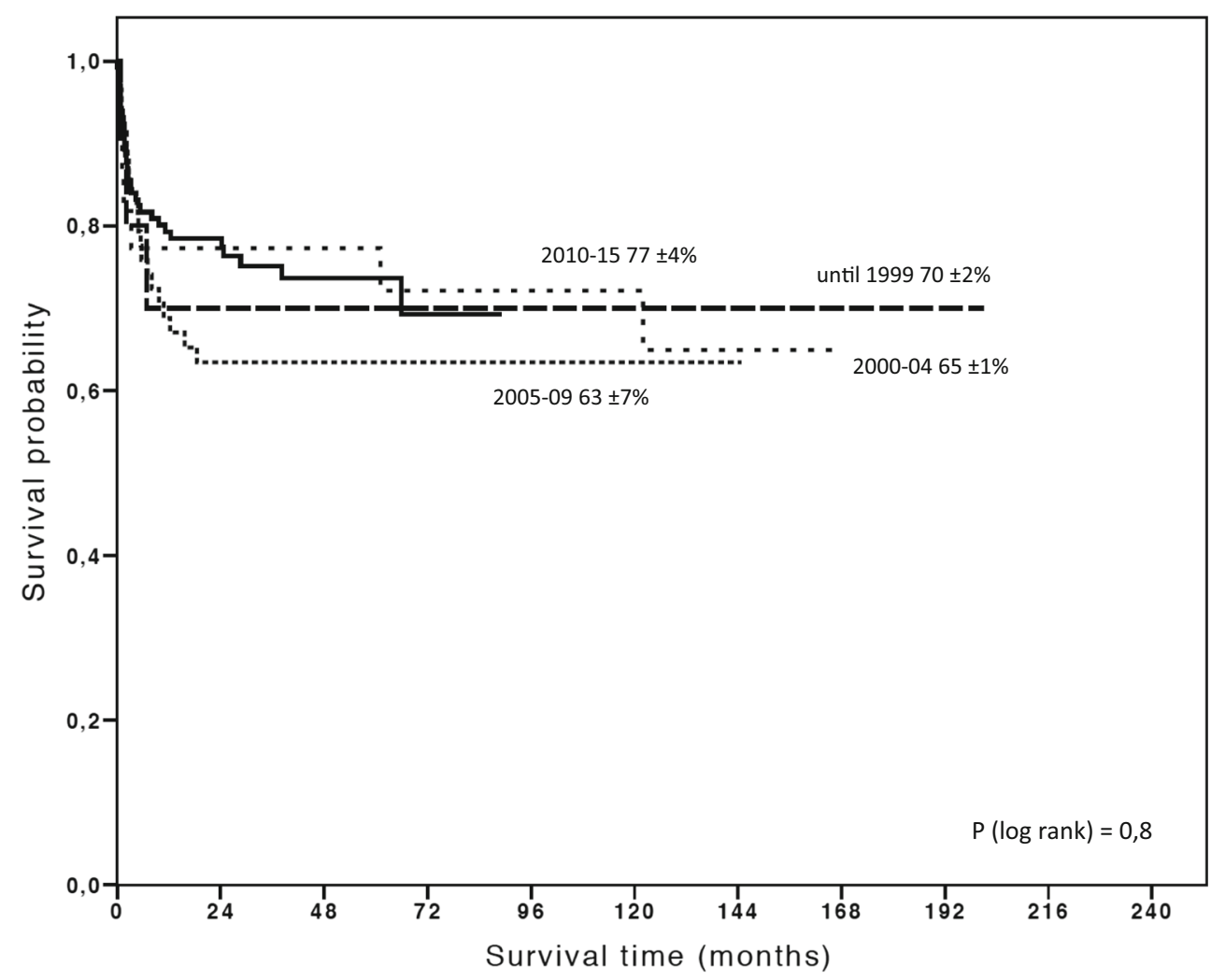


Table 3 Multivariate analysis for survival

\begin{tabular}{lclrl}
\hline Variable & HR & \multicolumn{2}{l}{$95 \%$ CI } & \\
\cline { 3 - 4 } & & Lower & Upper & \\
\hline Donor (ref. MSD) & & & & \\
MUD/MRD & 2.60 & 0.98 & 6.92 & 0.056 \\
MMRD & 3.36 & 1.00 & 11.30 & 0.050 \\
Source (ref. CB) & 2.27 & 1.22 & 4.23 & 0.010 \\
Year of transplant (ref. 1990-1999) & & & \\
2000-2004 & 1.29 & 0.32 & 5.25 & 0.721 \\
2005-2009 & 1.05 & 0.29 & 3.86 & 0.938 \\
2010-2015 & 0.78 & 0.22 & 2.74 & 0.702 \\
Age at BMT (months) & 1.01 & 1.00 & 1.01 & 0.055 \\
Gender (female) & 0.75 & 0.40 & 1.43 & 0.385 \\
Diagnosis (ref. SCID) & & & & \\
WAS & 0.35 & 0.17 & 0.76 & 0.007 \\
Other & 1.07 & 0.57 & 2.04 & 0.826 \\
\hline
\end{tabular}

Multivariate Cox regression

$M U D$ matched unrelated donor, $M R D$ matched related donor, $M M R D$ mismatched related donor, $C B$ cord blood, $P B S C$ peripheral blood stem cells, $S C I D$ severe combined immunodeficiency, WAS Wiskott-Aldrich syndrome

${ }^{\text {a }}$ Compared to BM or PBSC

vaccination complicates PID HSCT especially in SCID patients and death caused by BCG-associated complications is significantly more frequent in patients undergoing HSCT with localized or disseminated BCG-associated complications versus those with no manifestations [33]. Also in CGD, a study done with 73 patients in Latin America showed 30\% of BCG adverse reactions, $30 \%$ with severe complications [34]. Other risk factors commonly associated with poorer survival after transplants in patients with SCID are age at time of transplant (>3.56 months of age versus older) and the presence of active infection [35-37]. In our study, most SCID patients were transplanted after 6 months of age, reflecting diagnostic delay, late referral to a transplant unit, long time to find a compatible donor, and lack of beds in the few public hospitals that are able to perform this type of transplant. One limitation of our retrospective database is the incomplete information on active infectious complications of patients at time of transplant, so this influence could not be studied.

Despite the large number of volunteer donors registered worldwide, the chance of finding a MUD for patients of racially mixed backgrounds remains poor (http://bethematch.org). In 2015, the median time to find a MUD in Brazil was 85 days (personal communication). In an urgent situation like SCID, this time could significantly impact the success of transplantation. In the absence of a MSD or MUD, three alternatives could be considered for these patients: the use of unrelated mismatched cord blood, a MMUD, or a haploidentical related donor [36, 37]. In a study from the EBMT, T cell-depleted haploidentical donors and UCB had the same overall survival for patients with SCID [10]. Also in a more recent study, haploidentical transplants with $\mathrm{T}$ cell depletion without any type of conditioning regimen had good outcomes in SCID patients with active infections [37]. In these studies, however, MMRD transplants were performed with in vitro $\mathrm{T}$ cell depletion (CD34-positive cell selection or other methods) $[10,37]$. Unfortunately, this technique is expensive and rarely available in Brazil. Hence, for many years, UCB was easier and faster, and therefore used in almost $40 \%$ of our patients. More recently, haploidentical transplants with in vivo T cell depletion with post-transplant cyclophosphamide (PTCy) have been described in children and adults with hematological malignancies and non-malignant diseases [38-43]. This strategy is cheap and immediately available, and its applicability to treat PIDs has been reported in a small number of patients, but results are promising [44 47]. In the last 5 years, 12 of the patients with PID in our study underwent a first haploidentical transplant with PTCy. From these, seven patients engrafted and seven are alive at the last follow-up. That experience is rapidly increasing and rising to prominence in Brazil.

Taken together, the problems discussed above may explain the poorer survival seen from our cohort compared to those reported internationally, especially in patients with SCID. One measure that could change this scenario is newborn screening (NBS) for SCID. International studies are already reporting its important impact on HSCT outcomes [48, 49]. There are no established national programs for NBS in Brazil, but pilot studies are being conducted in some restricted regions [50, 51]. As the majority of patients with SCID in our cohort was transplanted beyond 6 months of age and mostly with active infections, introduction of NBS in our country could dramatically change SCID survival.

HSCT for WAS in our cohort was comparable to international series of patients with this disease [22, 24, 52, 53]. As the main institution treating PID in our country is a reference center for WAS, the relative frequency of this disease in our cohort is larger compared to other reports. Patients with WAS accounted for $30 \%$ of patients in our cohort. HSCT for CGD has improved since the development of reduced toxicity conditioning regimens and the use of treatment protocols guided by the EBMT/ESID group. In our cohort, 17 of 24 patients with CGD received the same conditioning regimen with a 5year overall survival of $80 \%$, which is comparable to international reports [21, 54].

Although we did not find a significant improvement in survival over the different time periods, we were able to significantly increase the number of patients treated over time: expanding the variety of diseases treated, increasing the use of alternative donors, and allowing patients with more severe diseases to have access to transplant. Participating in international protocols helped us standardize transplant techniques in our country, and close contact with international advisors allowed us to seek advice on difficult management problems. 
In conclusion, transplantation for PID patients in Brazil has evolved since the first procedure in 1990. Approaches to increase PID diagnosis, extend donor availability, and decrease transplant-related mortality from infections and graft versus host disease have led to better HSCT outcomes. Much work still has to be done to improve each of these factors. Increasing the number of centers with expertise in PIDs could make treatment available to more patients, and our cooperative group is doing this. The collaboration with international groups has been fundamental for our progress in this field, and continuity will further help us improve results. The experience in Brazil could also encourage other Latin American countries to provide better care for these patients. Future plans from our group include elaborating national guidelines for PID HSCT and further improve our study including detailed description of BCG and other infections before and after transplant as well as long-term follow-up and quality of life data.

Acknowledgments The authors thank all the nurses, physicians, and multidisciplinary staff of the participating centers.

Authorship Contribution JFF designed the study, enrolled and cared for patients, reviewed and analyzed data, and wrote the paper. CB and SN designed the study, enrolled and cared for patients, and reviewed the paper. All the other authors contributed to data collection, patient care, and reviewed the paper.

\section{Compliance with Ethical Standards}

This study was approved by the Institutional Review Boards of each center and performed in accordance with the 1964 Declaration of Helsinki.

Conflict of Interest The authors declare that they have no conflict of interest.

\section{References}

1. Picard C, Gaspar HB, Al-Herz W, Bousfiha A, Casanova JL, Chatila T, et al. International Union of Immunological Societies: 2017 primary Immunodeficiency Diseases Committee Report on Inborn Errors of Immunity. J Clin Immunol. 2018;38(1):96-128.

2. Gatti RA, Meuwissen HJ, Allen HD, et al. Immunological reconstitution of sex-linked lymphopenic immunological deficiency. Lancet. 1968;2:1366-9.

3. Bach FH, Albertini RJ, Joo P, et al. Bone-marrow transplantation in a patient with the Wiskott-Aldrich Syndrome. Lancet. 1968;2:1364-6.

4. Dvorak CD, Cowan MJ, Logan BR, Notarangelo LD, Griffith LM, Puck JM, et al. The Natural history of children with severe combined immunodeficiency: baseline features of the first fifty patients of the primary immune deficiency treatment consortium prospective study 6901. J Clin Immunol. 2013;33:1156-64.

5. Gennery AR, Slatter MA, Grandin L, Taupin P, Cant AJ, Veys $\mathrm{P}$, et al. Transplantation of hematopoietic stem cells and long term survival for primary immunodeficiencies in Europe: Entering a new century, do we do better? J Allergy Clin Immunol. 2010;126:602-10.
6. Slack J, Albert MH, Balashov D, Belohradsky BH, Bertaina A, Bleesing $\mathrm{J}$, et al. Outcome of hematopoietic cell transplantation for DNA double-strand break repair disorders. J Allergy Clin Immunol. 2017;S0091-6749(17):30567-5.

7. de la Morena MT, Leonard D, Torgerson TR, Cabral-Marques O, Slatter M, Aghamohammadi A, et al. Long-term outcomes of 176 patients with X-linked hyper-IgM syndrome treated with or without hematopoietic cell transplantation. J Allergy Clin Immunol. 2017;139(4):1282-92.

8. Griffith LM, Cowan MJ, Notarangelo LD, Kohn DB, Puck JM. Shearer et al. primary Immune Deficiency Treatment Consortium (PIDTC) update. J Allergy Clin Immunol. 2016;138(2):375-85.

9. Griffith LM, Cowan MJ, Notarangelo LD, Kohn DB, Puck JM, Pai SY, et al. Primary Immune Deficiency Treatment Consortium (PIDTC) report. J Allergy Clin Immunol. 2014;133(2):335-47.

10. Fernandes JF, Rocha V, Labopin M, Neven B, Moshous D, Gennery AR, et al. Transplantation in patients with SCID: mismatched related stem cells or unrelated cord blood? Blood. 2012;119(12):2949-55.

11. Leiva LE, Zelazco M, Oleastro M, Carneiro-Sampaio M, CondinoNeto A, Costa-Carvalho BT, et al. Primary immunodeficiency diseases in Latin America: the Second Report of the LAGID Registry. J Clin Immunol. 2007;27(1):101-8.

12. Condino-Neto A. The relevance of collaborative work: the Latin American Society for Immunodeficiencies (LASID) registry model. Clin Exp Immunol. 2014;178(Suppl 1):16-7.

13. Condino-Neto A, Sorensen RU, Gómez Raccio AC, King A, Espinosa-Rosales FJ, Franco JL. Current state and future perspectives of the Latin American Society for Immunodeficiencies (LASID). Allergol Immunopathol (Madr). 2015;43(5):493-7.

14. Espinosa-Rosales FJ, Condino-Neto A, Franco JL, Sorensen RU, Into action: improving access to optimum care for all primary immunodeficiency patients. J Clin Immunol. 2016;36(5):415-7.

15. Oliveira-Junior EB, Zurro NB, Prando C, Cabral-Marques O, Pereira PVS, Schimke LF, et al. Clinical and genotypic spectrum of chronic granulomatous disease in 71 Latin American patients: first report from the LASID Registry. Pediatr Blood Cancer. 2015;62:2101-7.

16. Costa-Carvalho B, González-Serrano M, Espinosa-Padilla S, Segundo G. Latin American challenges with the diagnosis and treatment of primary immunodeficiency diseases. Expert Rev Clin Immunol. 2017;13(5):483-9.

17. Fasth A. Osteopetrosis - more than only a disease of the bone. Am J Hematol. 2009;84(8):469-70.

18. Jaimovich G, Rolon JM, Baldomero H, Rivas M, Hanesman I, Bouzas L, et al. Latin America: the next region for haematopoietic transplant progress. Bone Marrow Transplant. 2017;52(5):798.

19. Gale RP, Seber A, Bonfim C, Pasquini M. Haematopoietic cell transplants in Latin America. Bone Marrow Transplant. 2016;51(7):898-905.

20. Carneiro-Sampaio M, Moraes-Vasconcelos D, Kokron C, Jacob CMA, Toledo-Barros M, Dorna MB, et al. Primary immunodeficiency diseases in different age groups: a report on 1,008 cases from a single Brazilian reference center. J Clin Immunol. 2013;33:716-24.

21. Güngör T, Teira P, Slatter M, Stussi G, Stepensky P, Moshous D, et al. Reduced-intensity conditioning and HLA-matched haematopoietic stem-cell transplantation in patients with chronic granulomatous disease: a prospective multicenter study. Lancet. 2014;383(9915):436-48.

22. Shekhovtsova Z, Bonfim C, Ruggeri A, Nichele S, Page K, Al Seraihy A, et al. A risk factor analysis of outcomes after unrelated cord blood transplantation for children with Wiskott-Aldrich syndrome. Haematologica. 2017;102(6):1112-9.

23. Eapen M, Ahn KW, Orchard PJ, Cowan MJ, Davies SM, Fasth A, et al. Long-term survival and late deaths after hematopoietic cell 
transplantation for primary immunodeficiency diseases and inborn errors of metabolism. Biol Blood Marrow Transplant. 2012;18(9): 1438-45.

24. Moratto D, Giliani S, Bonfim C, Mazzolari E, Fischer A, Ochs HD, et al. Long-term outcome and lineage-specific chimerism in 194 patients with Wiskott-Aldrich syndrome treated by hematopoietic cell transplantation in the period 1980-2009: an international collaborative study. Blood. 2011;118(6):1675-84.

25. Glucksberg H, Storb R, Fefer A, Buckner CD, Neiman PE, Clift RA, et al. Clinical manifestations of graft-versus-host disease in human recipients of marrow from HL-A-matched sibling donors. Transplantation. 1974;18(4):295-304.

26. Storb R, Prentice RL, Sullivan KM, et al. Predictive factors in chronic graft-versus-host disease in patients with aplastic anemia treated by marrow transplantation from HLA-identical siblings. Ann Intern Med. 1983;98(4):461-6.

27. Gaspar HB, Qasim W, Davies EG, Rao K, Amrolia PJ, Veys P. How I treat severe combined immunodeficiency. Blood. 2013;122(23): 3749-58.

28. Pai S-Y, Cowan MJ. Stem cell transplantation for primary immunodeficiency diseases: the north American experience. Curr Opin Allergy Clin Immunol. 2014;14(6):521-6.

29. Hassan A, Booth C, Brightwell A, Allwood Z, Veys P, Rao K, et al. Outcome of hematopoietic stem cell transplantation for adenosine deaminase-deficient severe combined immunodeficiency. Blood. 2012;120(17):3615-24.

30. Schuetz C, Neven B, Dvorak CC, Leroy S, Ege MJ, Pannicke U, et al. SCID patients with ARTEMIS vs RAG deficiencies following HCT: increased risk of late toxicity in ARTEMIS-deficient SCID. Blood. 2014;123(2):281-9.

31. Marciano BE, Huang CY, Joshi G, Rezaei N, Carvalho BC, Allwood Z, et al. BCG vaccination in patients with severe combined immunodeficiency: complications, risks, and vaccination policies. J Allergy Clin Immunol. 2014;133(4):1134-41.

32. Mazzucchelli JT, Bonfim C, Castro GG, Condino-Neto AA, Costa NM, Cunha L, et al. Severe combined immunodeficiency in Brazil: management, prognosis, and BCG-associated complications. J Investig Allergol Clin Immunol. 2014;24(3):184-91.

33. Marciano BE, Huang CY, Joshi G, Rezaei N, Carvalho BC, Allwood Z, et al. BCG vaccination in patients with severe combined immunodeficiency: complications, risks, and vaccination policies. J Allergy Clin Immunol. 2014;133(4):1134-41.

34. de Oliveira-Junior EB, Zurro NB, Prando C, Cabral-Marques O, Pereira PV, Schimke LF, et al. Clinical and genotypic spectrum of chronic granulomatous disease in 71 Latin American patients: first Report from the LASID Registry. Pediatr Blood Cancer. 2015;62(12):2101-7.

35. Buckley RH, Schiff SE, Schiff RI, Markert ML, Williams LW, Roberts JL, et al. Hematopoietic stem-cell transplantation for the treatment of severe combined immunodeficiency. N Engl J Med. 1999;340:508-16.

36. Antoine C, Müller S, Cant A, Cavazzana-Calvo M, Veys P, Vossen $\mathrm{J}$, et al. Long-term survival and transplantation of haemopoietic stem cells for immunodeficiencies: report of the European experience 1968-99. Lancet. 2003;361(9357):553-60.

37. Pai S-Y, Logan BR, Griffith LM, Buckley RH, Parrott RE, Dvorak $\mathrm{CC}$, et al. Transplantation outcomes for severe combined immunodeficiency, 2000-2009. N Engl J Med. 2014;371:434-46.

38. Luznik L, Jalla S, Engstrom LW, Iannone R, Fuchs EJ. Durable engraftment of major histocompatibility complex-incompatible cells after nonmyeloablative conditioning with fludarabine, lowdose total body irradiation, and posttransplantation cyclophosphamide. Blood. 2001;98(12):3456-64.

39. Luznik L, O'Donnell PV, Symons HJ, Chen AR, Leffell MS, Zahurak M, et al. HLA-haploidentical bone marrow transplantation for hematologic malignancies using nonmyeloablative conditioning and high-dose, posttransplantation cyclophosphamide. Biol Blood Marrow Transplant. 2008;14(6):641-50.

40. Brodsky RA, Luznik L, Bolaños-Meade J, Leffell MS, Jones RJ, Fuchs EJ. Reduced intensity HLA-haploidentical BMT with post transplantation cyclophosphamide in nonmalignant hematologic diseases. Bone Marrow Transplant. 2008;42(8):523-7.

41. Bolaños-Meade J, Fuchs EJ, Luznik L, Lanzkron SM, Gamper CJ, Jones RJ, et al. HLA-haploidentical bone marrow transplantation with posttransplant cyclophosphamide expands the donor pool for patients with sickle cell disease. Blood. 2012;120(22):4285-91.

42. Esteves I, Bonfim C, Pasquini R, Funke V, Pereira NF, Rocha V, et al. Haploidentical BMT and post-transplant Cy for severe aplastic anemia: a multicenter retrospective study. Bone Marrow Transplant. 2015;50(5):685-9.

43. Bonfim C, Ribeiro L, Nichele S, Loth G, Bitencourt M, Koliski A, et al. Haploidentical bone marrow transplantation with posttransplant cyclophosphamide for children and adolescents with Fanconi Anemia. Biol Blood Marrow Transplant. 2017;23(2):310-7.

44. Klein OR, Chen AR, Gamper C, Loeb D, Zambidis E, Llosa N, et al. Alternative-donor hematopoietic stem cell transplantation with post-transplantation cyclophosphamide for nonmalignant disorders. Biol Blood Marrow Transplant. 2016;22(5):895-901.

45. Shah NN, Freeman AF, Su H, Cole K, Parta M, Moutsopoulos NM, et al. Haploidentical related donor hematopoietic stem cell transplantation for dedicator-of-cytokinesis 8 deficiency using posttransplantation cyclophosphamide. Biol Blood Marrow Transplant. 2017;23(6):980-90.

46. Ouederni M, Mellouli F, Khaled BK, Kaabi H, Picard C, Bejaoui M. Successful haploidentical stem cell transplantation with posttransplant cyclophosphamide in a severe combined immune deficiency patient: a first report. J Clin Immunol. 2016;36(5):437-40.

47. Parta M, Hilligoss D, Kelly C, Kwatemaa N, Theobald N, Malech $\mathrm{H}$, et al. Haploidentical hematopoietic cell transplantation with post-transplant cyclophosphamide in a patient with chronic granulomatous disease and active infection: a first report. J Clin Immunol. 2015;35:675-80.

48. Kwan A, Church JA, Cowan MJ, et al. Newborn screening for severe combined immunodeficiency and T-cell lymphopenia in California: results of the first two years. J Allergy Clin Immunol. 2013;132:140

49. Baker MW, Grossman WJ, Laessig RH, Hoffman GL, Brokopp CD, Kurtycz DF, et al. Development of a routine newborn screening protocol for severe combined immunodeficiency. J Allergy Clin Immunol. 2009;124:522-7.

50. Kanegae MPP, Barreiros LA, Sousa JL, Brito MAS, Oliveira EB Jr, Soares LP, et al. Newborn screening for severe combined immunodeficiencies using trecs and krecs: second pilot study in Brazil. Rev Paul Pediatr. 2017;35(1):25-32.

51. Kanegae MPP, Barreiros LA, Mazzuchelli JTL, Hadachi SM, Guilhoto LMFF, Acquesta AL, et al. Neonatal screening for severe combined immunodeficiency in Brazil. J Pediatr. 2016;92(4):374-80.

52. Ozsahin H, Cavazzana-Calvo M, Notarangelo LD, Schulz A, Thrasher AJ, Mazzolari E, et al. Long-term outcome following hematopoietic stem-cell transplantation in Wiskott-Aldrich syndrome: collaborative study of the European Society for Immunodeficiencies and European Group for Blood and Marrow Transplantation. Blood. 2008;111(1):439-45.

53. Shin CR, Kim MO, Li D, Bleesing JJ, Harris R, Mehta P, et al. Outcomes following hematopoietic cell transplantation for WiskottAldrich syndrome. Bone Marrow Transplant. 2012;47(11):1428-35.

54. Morillo-Gutierrez B, Beier R, Rao K, et al. Treosulfan based conditioning for allogeneic haematopoietic stem cell transplantation in children with Chronic Granulomatous Disease. Multicentre experience on behalf of the EBMT Inborn Errors Working Party. Blood. 2016;128:440-8. 